Volume 8, No.1.1, 2019

International Journal of Advanced Trends in Computer Science and Engineering

Available Online at_http://www.warse.org/IJATCSE/static/pdf/file/ijatcse2981.12019.pdf

https://doi.org/10.30534/ijatcse/2019/2981.12019

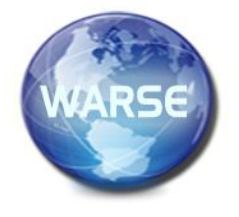

\title{
Hostel Service Quality Assessment among Technical Students
}

\author{
Pankaj Deshwal , Umang Soni ${ }^{1}$, Ayush Sultania ${ }^{1}$ \\ Netaji Subhas Institute of Technology, Delhi, India \\ pankajdeshwal@gmail.com \\ umangsoni.1@gmail.com \\ sultania.ayush7@gmail.com
}

\section{ABSTRACT}

This paper analyzes the perception of the quality of services provided to the hostel residents of an institute in New Delhi, India with respect to their expectations, by comparing them quantitatively. The items followed are broadly an adoption from existing literature. A Post Occupancy Evaluation is done to quantitatively analyze the service quality. Initially, a questionnaire was prepared over which responses were recorded from the residents of the hostel. The residents were asked to give their perception and expectation on all the listed aspects of the hostel. After getting the responses against all the questions, a gap score was calculated for each dimension, showing the difference between the expectation and the perception. A t-test was used for the research that shows standard deviation and standard mean error, and p-value. Most aspects of the hostel were found to have an expectation greater than their perception as recorded in the responses filled up by the residents. This paper will not only benefit the senior management in identifying the lacking factors of our hostels and improving the quality of living, food, and vanity of the hostel, but it will also provide better living conditions for the residents which will boost their working morale and would also implant a seed of healthy competition. The questionnaire was prepared by two methods: one was a literature review.

Key words: College, Hostel, Service, Quality, Engineering, Technical Institute

\section{INTRODUCTION}

Hostel life is an essential part of a student's life; it plays a major role in shaping the personality of a person. In college life, this is a vital ingredient in making a student prepared for his/her upcoming corporate life. This paper focuses on identifying and eventually improving the experiences of a student as being a hosteller. A quantitative analysis is presented where the students were asked to fill up their expectations from the hostel and again their perception about Those facilities were recorded after six months of their stay in the hostel. In the quantitative analysis, responses have been recorded from students of different age groups, attending the different course and hailing origin from a different part of the country through a questionnaire consisting of 42 statements and a demographic details subsection. Each statement within the questionnaire consisted of a factor that had two domains, for the resident's perception and expectation of the services offered at the hostel. The analysis of the perception and expectation of the students recorded on a 5-point Likert scale. The analysis was done using gap analysis. The research shows that the service quality according to a hosteller can be expressed as the difference of the perceived service and the expected service according to the respondent. The purpose of this paper is to analyze the perception of the quality of services provided to the hostel residents of an institute in New Delhi, India with respect to their expectations, by comparing them quantitatively.

\section{LITERATURE REVIEW}

A literature review is generally said to be the foundation of any paper, previous paper on similar topics cover all the recent developments in the respective area of concern. A quite profound and exhaustive literature review was conducted during and prior to the course of research. Papers relating to this topic and related to some of the similar topics were thoroughly studied. This paper gives a comparison between the expectations and perceptions of the residents. The parameters considered for quantification were adapted from some of the former paper written on same or similar topics.

For higher education institutions, the quality of service provided in the hostels serves as one of the facilities in the university, which defines academic productivity of its residents. [1] This quality of support services provided by the institution is the basis of higher academic productivity that further leads to a greater competitive advantage for the institute. Apart from the academic growth, the overall character and health development of the student is directly related to the facilities available at the institute. [2] The research model chosen for this paper is based upon the SERVQUAL model proposed by Parasuraman. [3] The service models put the focus on the aspects of the quality of service provided to the hostel residents in the technical institute. The intellectual capacities of the students can be broadened through providing quality service at student accommodation. [4] It is also proven that promising educational achievements and collaborative work can be possible through adequately planned accommodation facilities at a university. [5]

The SERVQUAL measurement and management model identifies five different ways of understanding customer 
experience, which are the differences between the following components:

Gap I Analysis: Customer Expectation and Management Perception about customer expectation

Gap II Analysis: Management Perception of services to be offered and specifications or standards of Service Quality Gap III Analysis: Service Quality standards and Perceived Service by the customers

Gap IV Analysis: Excessive Expectation generated through misunderstanding and Perceived Quality by the customers Gap V Analysis: Expected service by the consumer and Perceived Quality. [6]

The Gap value caused by the difference has a direct impact on the confirmation level perceived by the student. The individuals that are disconfirmed with the service quality provided by the hostel continue to promote their dissatisfaction. [7] Although the technical institute surveyed had a surplus demand of hostel amongst the day boarders, research also indicates that it is a lot easier to maintain and keep an existing customer than to create a new customer for the hostel. [8] This also indicates that dissatisfaction can also lead to residents vacating the hostel. Help was also taken from these previous research works. [9]

\section{METHODOLOGY}

The methodology (figure 1) of going about the analysis determines the lens through which the data has been analyzed i.e. tells about the vision of the author(s). In this paper the methodology followed was:

\section{Literature Review of Similar Topics}

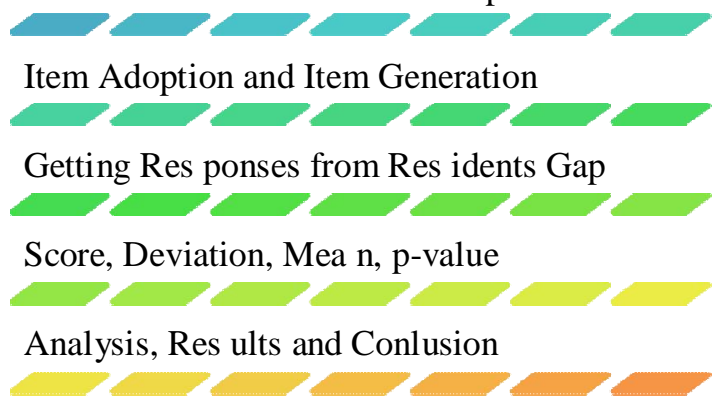

Figure 1: Methodology

Initially, the aim of writing this paper was figured out/decided by the authors, which was followed by an exhaustive literature review of papers written in same or similar fields. Some of the dimensions of this analysis were adapted from the paper(s) that were reviewed during this process and as per the discussions with the students [1]. The items were listed through this process.

After this, a suitable method was to be adapted for a good and just analysis of these items. Finally, a quantitative method of analysis was adapted. Further responses were recorded from the students, who were to join the hostel. The expectations of the students were recorded when they joined to the hostel. The same students were again asked for their responses and their perceptions about the hostel and their facilities were recorded after six months of their stay in their respective hostels. These responses were recorded from 206 residents from both boys' hostel and from the girls' hostel, of the residents pursuing the undergraduate or postgraduate degrees out of which three questionnaires were left out due to incomplete or randomized responses. The responses were recorded from the residents of varies age groups (ranging from 17-35).

After this, the recorded data was analyzed and a subsequent gap score, standard deviation, standard error mean, and a p-value was calculated for each of the items, comparing the value of their expectation and perception. There are three ways to ascertain SERVQUAL gap [10].

(1) Statement-by-statement analysis;

(2) Factor -by factor analysis; and

(3) Calculation of single service quality measure

In this research, the only first method was considered to ascertain the gap between perceptions and expectations. A ttest was used to examine the items gap. Total 42 null hypotheses and 42 alternate hypotheses were formulated for this study.

The Statements by statement null hypotheses are as follows:

$\mathrm{HO}_{\mathrm{l}}: \mu$ perMessstaff $-\mu$ expMessstaff $=0$

$\mathrm{HO}_{2}$ : $\mu$ perMessHygiene $-\mu$ expMessHygiene $=0$

$\mathrm{HO}_{3}: \mu$ perQualFood $-\mu$ expQualFood $=0$

Last three null hypotheses are:

$\mathrm{HO}_{40}: \mu$ perFurnArang $-\mu$ expFurnArang $=0$

$\mathrm{HO}_{41}$ : $\mu$ perOverComf $-\mu$ expOverComf $=0$

$\mathrm{HO}_{42}: \mu$ perOverSat $-\mu$ expOverSat $=0$

The Statements by statement alternate hypotheses are as follows:

$\mathrm{HO}_{1}: \mu$ perMessstaff $-\mu$ expMessstaff $\neq 0$

$\mathrm{HO}_{2}: \mu$ perMessHygiene $-\mu$ expMessHygiene $\neq 0$

$\mathrm{HO}_{3}$ : $\mu$ perQualFood $-\mu$ expQualFood $\neq 0$

Last three alternate hypotheses are:

$\mathrm{HO}_{40}$ : $\mu$ perFurnArang - $\mu$ expFurnArang $\neq 0$

$\mathrm{HO}_{41}: \mu$ perOverComf $-\mu$ expOverComf $\neq 0$

$\mathrm{HO}_{42}: \mu$ perOverSat $-\mu$ expOverSat $\neq 0$

The rejection of null hypothesis depends on the $\mathrm{p}$ values of the test. If the p-value is less than 0.05 , the null hypothesis shall be rejected. In this case, the alternate hypothesis is accepted and this would reveal that there is a significant difference between perception and expectation of item. 


\section{ANALYSIS, RESULTS, AND CONCLUSIONS}

\begin{tabular}{|c|c|c|c|c|c|c|c|}
\hline \multirow[t]{2}{*}{$\begin{array}{l}\dot{z} \\
\dot{n}\end{array}$} & \multirow[t]{2}{*}{$\stackrel{n}{\underline{\Xi}}$} & \multicolumn{2}{|l|}{$\sum_{\bar{\varpi}}^{\tilde{\Xi}}$} & \multirow[t]{2}{*}{ 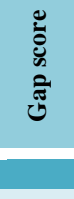 } & \multirow[t]{2}{*}{ 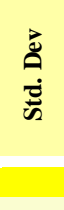 } & \multirow[t]{2}{*}{ 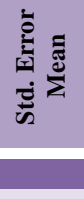 } & \multirow[t]{2}{*}{ 产 } \\
\hline & & Exp. & Per. & & & & \\
\hline 1 & $\begin{array}{l}\text { Mess Staff } \\
\text { services }\end{array}$ & $\ddot{\infty}$ & 管 & $\dot{\dot{0}}$ & $\dot{8}$ & $\dot{\dot{u}}$ & $\dot{8}$ \\
\hline 2 & Mess hygiene & $\stackrel{\vec{N}}{\text { U }}$ & $\stackrel{w}{\breve{L}}$ & $\dot{\vec{\omega}}$ & $\dot{\vec{u}}$ & $\dot{\Xi}$ & $\dot{8}$ \\
\hline 3 & Quality of food & $\ddot{u}_{u}^{w}$ & $\underset{\sim}{\omega}$ & i & $\overline{\tilde{N}}$ & $\frac{0}{6}$ & : \\
\hline 4 & $\begin{array}{l}\text { Modern } \\
\text { Equipment in } \\
\text { the hostel }\end{array}$ & $\underset{\sim}{\omega}$ & $\begin{array}{l}n \\
\stackrel{N}{\infty} \\
\dot{\infty}\end{array}$ & $\underset{\infty}{\infty}$ & $\dot{\tilde{I}}$ & $\stackrel{\circ}{\infty}$ & ஜे \\
\hline 5 & $\begin{array}{l}\text { Medical } \\
\text { facilities }\end{array}$ & $\stackrel{+}{+}$ & $\ddot{\phi}$ & $\stackrel{\dot{\leftarrow}}{ \pm}$ & $\bar{w}_{u}$ & ĩ & $\dot{8}$ \\
\hline 6 & $\begin{array}{l}\text { Artificial } \\
\text { lighting }\end{array}$ & $+\vec{i}$ & ă & $\stackrel{\dot{N}}{\text { N }}$ & $\bar{\omega}_{u}$ & ĩ & $\dot{8}$ \\
\hline 7 & Internet facility & $\dot{\dot{\alpha}}$ & $\bar{i}$ & $\stackrel{i}{\stackrel{\sim}{u}}$ & $\dot{\tilde{N}}$ & $\dot{0}$ & $\dot{8}$ \\
\hline 8 & $\begin{array}{l}\text { Availability of } \\
\text { Telephone } \\
\text { system }\end{array}$ & $\stackrel{w}{\tilde{o}}$ & $\stackrel{N}{\infty}$ & 产 & $\overrightarrow{\dot{\infty}}$ & 莕 & ஜ் \\
\hline 9 & $\begin{array}{l}\text { Mobile phone } \\
\text { network }\end{array}$ & $\stackrel{\omega}{\vec{\perp}}$ & $\stackrel{N}{=}$ & 产 & $\overline{\dot{\sigma}}$ & i्u & $\dot{8}$ \\
\hline 10 & Fire safety & $\begin{array}{l}w \\
w \\
+\end{array}$ & $\stackrel{\dot{\infty}}{+}$ & $\dot{\ddot{\sigma}}$ & $\dot{\vec{d}}$ & ĩ & $\dot{8}$ \\
\hline 11 & $\begin{array}{l}\text { Availability of } \\
\text { electricity }\end{array}$ & $\ddot{w}_{0}$ & $\overrightarrow{6}$ & $\dot{\dot{\infty}}$ & $\dot{a}$ & $\dot{\tilde{N}}$ & $\dot{8}$ \\
\hline 12 & $\begin{array}{l}\text { Backup for } \\
\text { power cuts }\end{array}$ & $\stackrel{\omega}{\stackrel{\omega}{\omega}}$ & $\overline{\dot{y}}$ & $\dot{\grave{a}}$ & i i & i & $\dot{8}$ \\
\hline 13 & $\begin{array}{l}\text { Water } \\
\text { availability }\end{array}$ & $\stackrel{\omega}{\omega}$ & $\bar{y}$ & $\dot{\dot{L}}$ & $\dot{\infty}$ & $\underset{i}{\dot{N}}$ & $\dot{8}$ \\
\hline 14 & $\begin{array}{l}\text { Quality of } \\
\text { Water }\end{array}$ & $\stackrel{\omega}{\sigma}$ & $\stackrel{\sim}{\tilde{\omega}}$ & $\begin{array}{l}\dot{1} \\
\dot{\omega}\end{array}$ & $\vec{i}$ & $\stackrel{0}{6}$ & 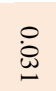 \\
\hline 15 & $\begin{array}{l}\text { Entertainment } \\
\text { facilities }\end{array}$ & $\underset{w}{w}$ & $\stackrel{N}{\sim}$ & $\underset{\dot{U}}{\dot{J}}$ & $\stackrel{\bar{i}}{i}$ & i & $\dot{8}$ \\
\hline 16 & $\begin{array}{l}\text { Implementation } \\
\text { of rules in the } \\
\text { hotel }\end{array}$ & $\underline{\omega}$ & $\ddot{8}$ & $\dot{9}$ & $\dot{a}$ & 芯 & $\dot{8}$ \\
\hline 17 & Security & $\ddot{d}$ & $\underset{\sim}{i}$ & 它 & $\underset{\sim \sim}{i}$ & $\stackrel{0}{6}$ & : \\
\hline 18 & $\begin{array}{l}\text { Safety from } \\
\text { thefts }\end{array}$ & $\stackrel{\vec{\omega}}{0}$ & $\begin{array}{l}w \\
\vec{t}\end{array}$ & $\dot{8}$ & $\dot{\bar{\perp}}$ & 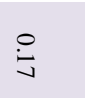 & $\dot{8}$ \\
\hline
\end{tabular}

19 Hostel

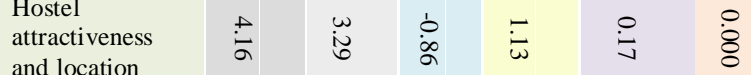

20 Natural

Natural

ghting

21 Overall

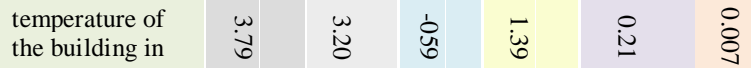

winters

22 Overall

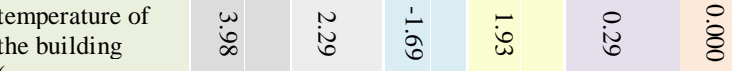

(summer

23 Air quality

24 Ventilation

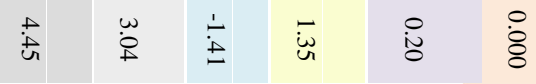

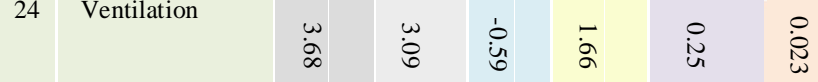

25 Outside noises $\begin{aligned} & \omega \\ & \text { in }\end{aligned}$

26 Space for car

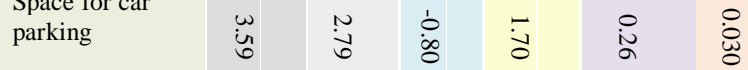

$27 \begin{aligned} & \begin{array}{l}\text { Availability of } \\ \text { conveniences }\end{array} \\ & \dot{\infty}\end{aligned}$

$28 \quad$ Overall

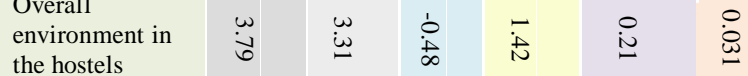

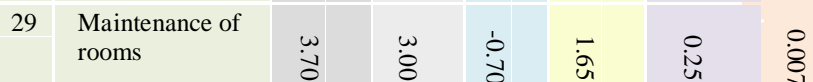

30 Overall

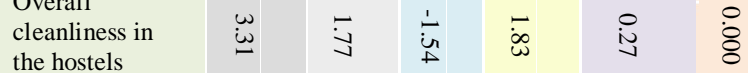

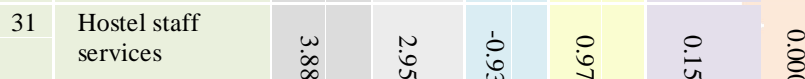

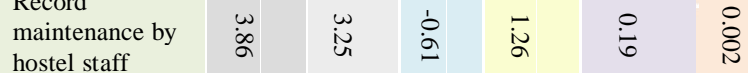

33 Responsiveness

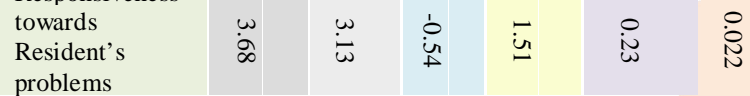

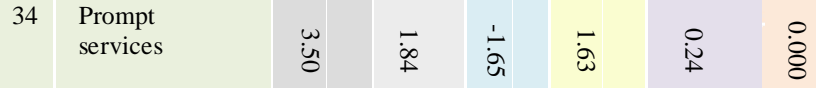

35 Behaviour of

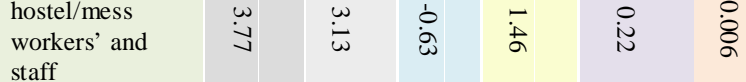

36 Room space

$37 \quad$ Visual and conversational privacy of rooms

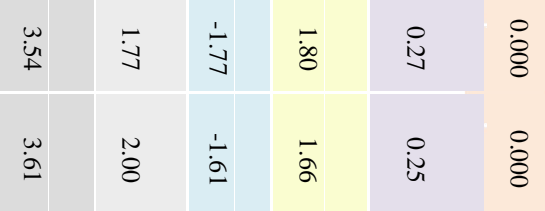




\begin{tabular}{|c|c|c|c|c|c|c|}
\hline 38 & $\begin{array}{l}\text { Interior design } \\
\text { of rooms }\end{array}$ & $\dot{\omega}$ & $\underset{\omega}{\omega}$ & 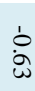 & $\bar{\omega}_{\infty}$ & $\stackrel{\text { N }}{\text { D }}$ \\
\hline 39 & $\begin{array}{l}\text { Quality of } \\
\text { furniture in } \\
\text { rooms }\end{array}$ & iv & $\overline{\vec{\sigma}}$ & $\frac{\dot{m}}{\dot{b}}$ & $\dot{a}$ & ì \\
\hline 40 & $\begin{array}{l}\text { Furniture } \\
\text { arrangement }\end{array}$ & $\stackrel{\overrightarrow{\dot{c}}}{\mathrm{u}}$ & $\underset{\omega}{\omega}$ & $\begin{array}{l}\dot{1} \\
\infty \\
\infty\end{array}$ & $\overline{\bar{\omega}}$ & $\stackrel{\circ}{\square}$ \\
\hline 41 & $\begin{array}{l}\text { Overall } \\
\text { comfort level }\end{array}$ & is & $\begin{array}{l}N \\
\infty \\
\infty\end{array}$ & $\stackrel{1}{\dot{0}}$ & $\overline{\text { th }}$ & 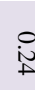 \\
\hline 42 & $\begin{array}{l}\text { Overall } \\
\text { satisfaction }\end{array}$ & $\dot{\sim}$ & $\stackrel{\tilde{N}}{\sim}$ & $\stackrel{\dot{u}}{u}$ & $\bar{\omega}$ & i \\
\hline
\end{tabular}

Figure 2: Hypothesizes Result

The result of all hypothesizes (figure 2) shows the rejection of all 42 null hypothesizes and acceptance of all 42 alternate hypotheses. Therefore, there is a significant difference between the means of all 42 items. The conclusions drawn from the analysis of each dimension is as follows:

Mess Staff services: A moderate gap is observed in the expected and the perceived scores. This aspect needs to be worked upon. Mess hygiene: This is considered as one of the most important aspects, but this also needs to be worked upon. The quality of food: There is quite a little gap between the perception and expectation scores. This only needs some improvement. Modern equipment (This aspect shows that all the equipment that used in the hostel is modern or primitive): residents about this aspect have depicted not much. Medical facilities: Another one, which is among the most important, but there, seems to be some dis-satisfaction among the residents. This is an aspect, which needs to be worked upon immediately. Artificial lighting: There is some scope for improvement in this aspect, as a gap score of 0.72 cannot be neglected. Internet facility: This is the one with the maximum gap score. It is supposedly the poorest aspect of living provided by the administration. Availability of telephone system: the residents in this aspect demand considerable improvement as well. Mobile phone network: This is an aspect, which is quite hard to be worked on by the administration because this being an aspect not set up by them or something, which they cannot control. This is also having a substantial gap score and needs a good amount of improvement.

Fire safety: This is an aspect, which has been very poorly controlled and organized by the administration, which is quite evident from the gap score. Availability of electricity: In this modern world, electricity is considered a need rather than a commodity. 1.68 being a large gap score shows that there is a need of quite a good amount of improvement. Backup for power cuts: This too is in a similar condition as that its availability. Some back-up probably gen-sets are a demand of the residents. Water availability: Water being essential for life, needs to be always more than its demand. However, the residents are quite dissatisfied by their present condition. The quality of water: This aspect also does not satisfy the needs of the residents and is supposedly a point of contention for the administration. Water seems to be an important aspect to be worked on by the administration.
Entertainment facilities: Since this being, a hostel for students, entertainment plays an important role. There is the scope of some improvement in this aspect. Implementation of rules in the hostel: Rules play an important role in the overall running, maintenance, and quality of the hostel. However, this seems to be an issue of contention for the administration. Security: Unlike the 16th point (Implementation of rules); this gives a gap, which is quite unexpected. Good security means better safety, this is a very important aspect, and it seems that it is very well maintained and safety of the residents is not taken for granted. Safety from thefts: This aspect needs some improvement, but as per the administration, this more depends on the residents than on the administration. Hostel attractiveness and location: Another one of the important aspects (location), the residents seem to be a bit less satisfied with this aspect. Natural lighting: It has quite a less gap score as compared to the other aspects; this aspect itself shows that the hostel has been built at a good location. Overall temperature in winters: Shows at-least some satisfaction from the residents.

Overall temperature in summers: This is very much opposite to what we observe in the above aspect. Air quality: The quality of the air has a direct impact on the health of the person breathing it; this is another issue of contention for the administration. Ventilation: Ventilation helps in keeping the air quality good; this is contradictory to the above aspect. Outside noises: Seems to be an aspect of which most of the residents are satisfied. Space for car parking: Another point of contention, which could be worked upon by the administration. Availability of conveyances: This entirely depends on the location of the institute, which cannot be worked much by the administration.

The overall environment in the hostel: This is one of the strong attractions for the residents for residing in the hostel. A good environment in the hostel makes the overall stay of the resident quite positive. Maintenance of rooms: Most of the residents seem to be satisfied with the aspect, but there is always some scope of improvement. Overall cleanliness in the hostel: This is another folly on the part of the administration, which needs to be improved. Hostel staff services: On this aspect, around $50 \%$ of the residents seem to be satisfied and rest being not, this is another aspect improvement of which entirely lies in the hands of the administration. Record maintenance: This seems to be another positive point on the part of the administration; this could further be improved up until some extent.

Responsiveness towards the resident's problems: As per the recorded responses, this gives a positive image of the administration. However, no residents seem to be satisfied. Prompt services: This gives a result, which gives a quite different image as portrayed in the above aspect. The behavior of hostel/mess worker's and staff: This aspect portrays a good image of the mess/hostel workers'/staff; this is also of the reason(s), which adds up to the environment of the hostel. Room space: A dissatisfaction is very much evident from the recorded responses. This could be a reason of accommodating more residents in less space. This could be worked upon by the administration by building new hostels. 
Visual and conversation privacy of rooms: Another point of improvement for the administration. The interior design of rooms: The responses show some satisfaction with this aspect, but there is always some scope of improvement. The quality of furniture in the rooms: An aspect depending on the administration to a very large extent. This is also an aspect, which needs quite a lot of improvement. Furniture arrangement: This is something very specific to the resident himself/herself. On the part of the administration, the size of the furniture should be in proportion to the size of the $\operatorname{room}(\mathrm{s})$. Overall comfort level: A gap score of 1.09 is observed in the overall comfort level, which seems to be quite achievable and gettable on the part of the administration to reduce it to a smaller value until the evaluation. Overall satisfaction: A gap score of 0.75 is observed in the overall satisfaction.

\section{CONCLUSIONS AND FUTURE RESEARCH}

The number of responses collected to analyze expectation and perception is one limitation. Therefore, it is suggested to collect more data in future to grasp data that are more representative. This study is limited to only technical institutions so in future; studies can be conducted in non-technical institutions. Some studies can be conducted linking service quality with satisfaction, loyalty, word-of mouth [11, 12, 13]. A comparative study can also be conducted. A similar type of study can be conducted in other metropolitan cities of India.

\section{REFERENCES}

[1] Y. Adewunmi, M. Omirin, F. Famuyiwa, and O. Farinloye, "Post-occupancy evaluation of postgraduate hostel facilities", Facilities, vol. 29, no. 3/4, pp. 149-168, Mar. 2011. https://doi.org/10.1108/02632771111109270

[2] I. Price, F. Matzdorf, L. Smith, and H. Agahi, "The impact of facilities on student choice of university" Facilities, vol. 21 , no. 10 , pp. 212-222, Oct. 2003. https://doi.org/10.1108/02632770310493580

[3] A. Parasuraman, L. L. Berry, and V. A. Zeithaml, "More on improving service quality measurement", Journal of Retailing, vol. 69, no. 1, pp. 140-147, Mar. 1993. https://doi.org/10.1016/S0022-4359(05)80007-7

[4] N. Ulyani Mohd Najib Nurul, N. Aini Yusof and N. Zainul Abidin, "Student residential satisfaction in research universities", Journal of Facilities Management, vol. 9, no. 3, pp. 200-212, Jul. 2011. https://doi.org/10.1108/14725961111148108

[5] M. A. Hassanain, "On the performance evaluation of sustainable student housing facilities", Journal of Facilities Management, vol. 6, no. 3, pp. 212-225, Jul. 2008. https://doi.org/10.1108/14725960810885989

[6] J. J. Cronin, M. K. Brady and G. T. M. Hult, "Assessing the effects of quality, value, and customer satisfaction on consumer behavioral intentions in service environments", Journal of Retailing, vol. 76, no. 2, pp. 193-218, Jun. 2000. https://doi.org/10.1016/S0022-4359(00)00028-2

[7] R. L. Oliver, "Effect of expectation and disconfirmation on post exposure product evaluations: An alternative interpretation" Journal of Applied Psychology, vol. 62, no. 4, pp. 480-486, 1977. https://doi.org/10.1037/0021-9010.62.4.480

[8] W. Reinartz, J. S. Thomas, and V. Kumar, "Balancing acquisition and retention resources to maximize customer profitability", Journal of Marketing, vol. 69, no. 1, pp. 6379, Jan. 2005. https://doi.org/10.1509/jmkg.69.1.63.55511

[9] [P. Deshwal, V. Ranjan, and G. Mittal, "College clinic service quality and patient satisfaction", International Journal of Health Care Quality Assurance, vol. 27, no. 6, pp. 519-530, Jul. 2014

https://doi.org/10.1108/IJHCQA-06-2013-0070

[10] F. Buttle, "SERVQUAL: review, critique, research agenda", European Journal of Marketing, Vol. 30 No. 1, pp. 8-32, 1995. https://doi.org/10.1108/03090569610105762

[11] P. Deshwal and P. Bhuyan, "Cancer patient service experience and satisfaction," International Journal of Healthcare Management, pp. 1-8, Nov. 2016.

[12] P. Deshwal, "Customer experience quality and demographic variables (age, gender, education level, and family income) in retail stores," International Journal of Retail \& Distribution Management, vol. 44, no. 9, pp. 940-955, Sep. 2016. https://doi.org/10.1108/IJRDM-03-2016-0031

[13] P. Deshwal and A. Krishna. Customer service experience and satisfaction in retail stores. In 20163 rd International Conference on Computing for Sustainable Global Development (INDIACom), IEEE, 2016. 